Koskela, L., Tezel, A., and Tzortzopoulos, P. (2018). "Why visual management?" In: Proc. $26^{\text {th }}$ Annual Conference of the International. Group for Lean Construction (IGLC), González, V.A. (ed.), Chennai, India, pp. 250-260. DOI: doi.org/10.24928/2018/0527. Available at: www.iglc.net.

\title{
WHY VISUAL MANAGEMENT?
}

\author{
Lauri Koskela $^{1}$, Algan Tezel ${ }^{2}$ and Patricia Tzortzopoulos ${ }^{3}$
}

\begin{abstract}
From early on, visual management (VM) has been an intrinsic ingredient of the Toyota Production System (TPS) and its derivatives like lean production. Akin to the evolution of most other parts of the TPS, it has been developed through practitioner efforts rather than being propelled by theoretical insights. Recently, scholars have started to create a theoretical knowledge base for VM. Besides taxonomies of visual devices and their functions, there is only one fully fledged theory of VM, based on the concept of affordance. It is contended here that the scholarly field of visual management has been too narrowly defined. In fact, research on (or bearing on) visual devices has been carried out in several other, mostly small fields, often with little mutual awareness. A review on the theoretical explanation of VM is provided, based on this wider literature. The concept of affordance has been used in this context already in early 1990s. This focuses attention especially to the human cognitive capabilities and corresponding features of visual devices. Generally, VM is argued to provide a more rapid and reliable mode of communication in comparison to traditional alternatives. VM is thus compatible with the lean tenets of time compression and variability reduction. This explains its central role in lean production.
\end{abstract}

\section{KEYWORDS}

Visual management, lean production, cognition

\section{INTRODUCTION}

From early on, visual management (VM) has been an intrinsic ingredient of the Toyota Production System (TPS) and its derivatives like lean production. Akin to the evolution of most other parts of the TPS, it has been developed through practitioner efforts rather than being propelled by theoretical insights. Recently, scholars have started to create a theoretical knowledge base for VM. One reason for the attention to theory has been the insight that design guidelines for visual devices are badly needed (Valente \& al. 2017), and theoretical knowledge is necessary for creating such guidelines.

Professor, School of Art, Design and Architecture, University of Huddersfield, 1.koskela@ hud.ac.uk

Lecturer, School of Art, Design and Architecture, University of Huddersfield, a.tezel@hud.ac

Professor, School of Art, Design and Architecture, University of Huddersfield,

p.tzortzopoulos@hud.ac.uk 
Besides taxonomies of visual devices (Galsworth 1997) and their functions (Tezel \& al. 2009), there is only one fully fledged theory of VM, developed by Beynon-Davies and Lederman (2017). Thus, it would be tempting to hold their statement true: "there is little theorisation of how the visual device provides value to the wider system of operation". However, this statement can be challenged. It is contended here that the scholarly field of VM has been too narrowly defined. In fact, research on (or bearing on) visual devices has been carried out in several other, mostly small specialized fields, often with little mutual awareness. Insights relevant on VM can be found in Cognitive engineering (Wilson \& al. 2013), Human Factors engineering (Wickens \& al. 2014), Healthcare informatics (Xiao 2005), Human-Computer Collaborative Work (Maher \& al. 1996), Information visualization (Eppler \& Bresciani 2013) and management studies into the visual (Bell \& Davison 2013).

In this paper, a review on the theoretical explanation of VM is provided, based also on this wider literature. The aim here is neither to build a theory of VMnor to discuss VM in any particular industry, but to pinpoint to phenomena and theories that seem promising and useful, both for theorising and for practical implementation. The paper is structured as follows. The next section introduces the recent affordance theory of VM and presents critical remarks on it. Then, further ingredients for theorising on VM are presented, inspired by the wider literature. The paper is completed by conclusions.

\section{AFFORDANCE THEORY OF VISUAL MANAGEMENT AND ITS CRITIQUE}

\section{AFFORDANCE THEORY OF VISUAL MANAGEMENT}

As far as it is known, the only major attempt to theorise on VM is the suggestion of Beynon-Davies and Lederman (2017) to use the affordance theory as an explanatory lens. Affordance theory was presented by Gibson in 1977.The basic idea is that an affordance is what the environment provides for a human or an animal ${ }^{4}$. These, in turn, require compatible effectivities, in the form of cognitive or action capabilities. In BeynonDavies' and Lederman's (2017) encapsulation, “an affordance is an opportunity for action made possible both by the effectivities of the actor and by structures in the environment". Based on an examination of practical cases, they define three layers or domains, i.e. (a) articulation, (b) communication and (c) coordination, connected by the affordances of the visual devices. It is recognised by Beynon-Davies and Lederman (2017) that the definition of affordances by Gibson is not sufficient for covering what happens in VM. Thus, they distinguish between first order affordance, i.e. how the articulation of physical objects allows communication, and second order affordance, which connects communicative action with coordinated work actions.

4 However, the affordance theory is not the first endeavour to characterize the interaction between living organisms and their environment. Already 1926 von Uexküll presented his theory on the world of living organisms, Umwelt. Arguably, the essential ideas of affordances were present. 
Beynon-Davies and Lederman (2017) crystallize their explanation of visual devices within wider visual systems into four features: (1) These systems involve the use of material and typically highly visual(tangible) artefacts for information purposes; (2) The physical manipulation of such artefacts in relation to each other is important to informing actors within group work; (3) The overall state of the physical environment in which such manipulation takes place is also important to informing actors; (4) The manipulation of physical and visual artefacts is important to support situated choice.

Based on their theoretical work, Beynon-Davies and Lederman (2017) present five prescriptions for developing VM - unfortunately a short summary cannot convey the full depth of these: (1) Visual devices should be thought as multimodal, thus utilizing all senses; (2) Visual devices should be thought of in terms of facilitating action-taking; (3) Physical structures such as whiteboards should be thought as performative structures (how to communicate and what work would result from such communication; (4) The designer of VM should not consider an individual device but should consider the whole physical environment; (5) Patterns of action should be thought of either as-is, as-if or tobe(this essentially refers to embracing current status, targeted status and change in development of visual management).

\section{CRITICAL DISCUSSION}

The affordance theory is a valuable advance in understanding visual management. Unfortunately, it falls short in several respects:

- The discussion is centred around collaborative devices of VM; these are important but leave the similarly important types of visual devices addressing individual work aside.

- The theory does not explain why visual management is preferred in some approaches to management, and not paid attention to in other approaches.

- The term affordance is at a high level of abstraction; according to Gibson (1979), it is "something that refers both to the environment and the animal", "it implies the complementarity of the animal and the environment". It may give an illusion of explanation although it does not detail what precisely is the nature of complementarity, say in terms of characteristics of an artefact and cognitive abilities of the actor.

- The theory is not comparative: as such, it has limited practical use as it does not clearly describe which types of situations or work actions would benefit from VM devices.

- The development of this affordance-based VM theory did not take into account that there has been an approach based on affordances since early 1990’s, namely Ecological Interface Design (Vicente \& Rasmussen 1990).

\section{FURTHER INGREDIENTS TO THE THEORY OF VISUAL MANAGEMENT}

Our starting point is that VM requires a multi-faceted and multi-level theoretical explanation. We do not attempt to present a fully developed theoretical framework here 
but rather provide examples of viewpoints and domains that will be relevant in the further consolidation of the theory of visual management.

\section{DIRECT AND RAPID ACCESS TO INFORMATION}

Beynon-Davies and Lederman (2017) state, without further justification: "Affordances have the potential to be perceived directly by actors without any intermediate, conscious, cognitive processing." Similar statements can be found from books on VM by practitioners. How can this be explained?

We contend that the question about the existence of two modes of cognition, discussed long since. It is appropriate to start from the discussions on left and brain brainhalves. For example, Springer and Deutsch (1993) give a neurologically justified (in that time) view on these:

- Left Hemisphere: Verbal; sequential; temporal, digital; logical; analytical; rational; Western thought

- Right Hemisphere: Nonverbal; visuospatial; simultaneous; spatial; analogical; Gestalt; synthetic; intuitive; Eastern thought

Afterwards, along with evolving methods to research the brain, it has been realised that this view is too simplified. However, the basic idea of two different modalities of brain functions remains. A popular interpretation is given by Kahneman (2011), who describes two systems of the mind:

- System 1 operates automatically and quickly, with little or no effort and no sense of voluntary control

- System 2 allocates attention to the effortful mental activities that demand it, including complex computations. The operations of System 2 are often associated with the subjective experience of agency, choice, and concentration

The importance of allocating a given information requirement to either of these systems is illustrated through the following quote, where the issue is approached through cognitive engineering (Hettinger, Roth \& Bisanz 2017):

Cognitive work requirements take the form of questions a user must be able to answer 'at a glance' without needing to traverse multiple screens, perform mental calculations, or integrate disparate pieces of information [...]. Detailed information and display requirements are then specified to satisfy the cognitive work requirements.

Broadly, it can be stated that visual information is captured by System 1 and comprehension of written information by System 2. Images can be recognised in 13milliseconds (Lewis 2014), while an ordinary reader will read 200 - 230 words per minute ( $3-4$ words per second). Thus, there is reason to believe that visual management shows sheer superiority in terms of the speed of the capture of a conveyed message in comparison to arrangements where messages are written or oral. However, currently there is hardly any empirical evidence on this performance difference specifically acquired from a VM context. Likewise, there is little research comparing different designs of visual devices regarding speed of capture (which of course is only one of thecriteria to study). 


\section{RELIABILITY IN COMPREHENSION}

There are many indications showing that reliability of the comprehension of the messages in VM is an important characteristic. For example, visual devices have been classified according to the level at which they constrain action, in other words, reliably lead to the correct action (Galsworth 1997). At the highest level of reliability are fool-proof mechanisms, poka-yoke, which usually are not dependent on human senses but operate through physical implements ${ }^{5}$. Further, indirect evidence is provided by the fact that VM has persistently been used in contexts requiring high reliability, such as air traffic control, healthcare and generally in high-reliability organisations.

Again, visual messages can be compared to written messages. Reading is dependent on decoding the written words, and capturing their meaning (comprehension). Regarding both decoding and comprehension, considerable performance variation is reported already in university student population (Landi 2010).As discussed above, capturing the meaning of an image is more direct, which as such reduces the potential for mistakes. In the context where VM is used, the visual images and symbols are well-known (except for novices), which again reduces the proneness to mistakes. The hypothesis that VM leads to higher reliability has broad justification, but specific empirical studies are missing.

\section{PROJECTION OF INTERNAL MENTAL MODELS: SPRACTION}

In air traffic control, the controllers have in the past written basic information regarding each flight on a paper strip. Then, for example, the order of approaching flights is indicated by the order of the strips on a rack tailored for this purpose. There have been various attempts to computerise this work process, but the controllers have often persisted with these manual methods. Why so?

In closer examination, it has been found that by organising the strips, an air traffic controller is projecting his internal mental model into a physical artefact. In turn, this physical artefact works then as an aide-memoire for her (MacKay 1999):

Controllers report that they develop a rich mental image of the traffic during the course of a session. The current strip set up reduces the controller's mental load, allowing them to retain only the important details, since the rest of the information is always instantly accessible in front of them. The physical strips can be viewed as a concrete component of their mental representation, helping them handle more information and successfully deal with interruptions.

However, physical direct action is an indispensable element in this cognitive process; MacKay (1999) describes:

Most controllers, when taking over a control position, physically touch each strip, rearranging some of them. Reordering the stripshelps controllers mentally register the new traffic

5 The question arises whypoka-yoke should be discussed as part of visual management. The terminology is not settled in this area. The term "visual controls" is often used narrowly, to refer only to visual devices. However, in the literature, "visual management" is often used as a short-hand for communication also through visual and other senses (Tezel \& al. 2016). Mechanical, electronic and other poka-yoke devices, not based on sensory perception, are also included (Galsworth 1997). 
situation. In each case, it is the act of rearranging the strips, more than the final layout, that is important.

And further (MacKay 1999):

Controllers sometimes use both hands together, sliding them down both sides of the strip board as they review the set of flights or look for a particular flight. They usually stop, resting a finger on the relevant strip. Student controllers can be observed "thinking out loud with their hands" as they touch each individual strip involved in a particular conflict.

What is happening in this process can be understood through the theory developed by Tversky $(2011,2015)$.She argues that when thought overwhelms the mind, the mind puts it into the world, in diagrams or gestures; a thought is projected into the world. Thus, human actions organise space to convey abstractions; she calls this spraction. Physical action is thus seen as a direct extension of thinking. Thus, creating or interacting with a model through the computer cannot substitute this integrated mental-physical act of spraction.

Other examples of spraction include the physical boards used in healthcare to plan the occupation of beds in a ward (Xiao 2005). In the sphere of construction, the practice of collaborative planning, with stakeholders positioning tasks marked on Post-it notes into a timeline on a paper attached to the wall, represents likewise this phenomenon. Also sketching and model-making in design arguably represent spraction.

\section{MATCHING VISUAL DEVICES WITH DIFFERENT COGNITIVE/ACTION CAPABILITIES}

The SRK taxonomy, developed by Rasmussen (Vicente \& Rasmussen 1992) in terms of an affordance based approach called Ecological Interface Design, originally for industrial process plant control, refers to skill, rule and knowledge based response of operatives in a work situation. A skill based response is automatic, triggered by the perception of a need for action. A rule based response requires a selection of a rule compatible with the situation, and its implementation. A knowledge based response is needed in a surprising/rare situation, where the background knowledge of the operative on the process needs to be mobilised for problem solving.

The SRK-model contains design guidelines on the user interface of process control regarding the different responses. One design rule is to encourage the use of skill and rule based behaviour when possible, to save on scarce cognitive resources.

Arguably, in the practice of visual management systems, it has been possible to create support to all three types of responses: (1) For skill based responses, visual devices that directly trigger the needed action (like a reflex) are preferred; (2) For rule based responses, the relevant rules are provided for immediate inspection, say through One Point Lesson displays; (3) For knowledge based responses, standardized problem solving methods, such as the A3 method, are utilised. 


\section{COMMON GROUND, SITUATIONAL AWARENESS AND SHARED UNDERSTANDING}

\section{Common ground}

A widely-knownpiece of classical rhetorical knowledge concerns "common ground", the shared values, facts and presumptions between the orator and the audience. This concept, seminally presented by Aristotle, has been re-discovered and generalised several times in more recent times.

Clark and Brennan (1991) contend that in communication, common ground cannot be properly updated without a process they call grounding. For example, grounding can take the form of referring to objects and their identities, through say, indicative gestures, such as pinpointing. Klein et al. (2005) extend the discussion on common ground to joint activity and related team coordination. The mentioned authors have further studied the loss of common ground, and list a number of mechanisms leading to that. One type, confusion on who knows what, is occurring so frequently that it has been named as Fundamental Common Ground Breakdown (Klein et al. 2005).

\section{Situational awareness}

Situational awareness can be defined as the capacity to perceive and comprehend the characteristics of an environment within time and space supporting the realisation of predicted futures aligned with a task or project (Koskela \& al. 2016).

\section{Shared understanding}

Shared understanding of the problem is a concept emerging from studies on design teams (Cross and Cross 1996, Maher et al. 1996). It has been found that design teams spend a lot of effort to reach shared understanding of the problem, and to manage conflicts based on different interpretations of ideas, concepts and representations.

\section{Visual management supporting common ground, situational awareness and shared understanding}

The relation of visual information and common ground has recently started to be studied (Kraut et al. 2002). Research shows that visual information supports conversational grounding (Gergle et al. 2013). Methods of VM seem often to be geared towards the creation of common ground. Especially, the practice of the Big Room (obeya) seems to be a paramount means towards creating a broad and solid common ground in product development or facility design.

Especially, public displays seem effective for avoiding the Fundamental Common Ground Breakdown and creating situational awareness (Xiao 2005):

...the public display of assignments provides a way for individuals or teams to visualize current team activities and resource availability, so that everyone knows what everyone else knows about resource status.

In the area of (general) management, business model canvas, a standardized visual way of presenting a business model has recently been advanced (Osterwalder \& Pigneur 2010). Based on this idea, templates for project model canvas and life cycle canvas have 
recently been developed (Medeiros 2017). All these canvases seem to promote the creation of common ground and shared understanding.

The role of Building Information Models (BIM)in creating common ground and shared understanding has recently been addressed ${ }^{6}$ in the literature. Miettinen and Paavola (2016) comment on one-day design meetings where the model has been projected on a screen on the wall - this can be compared to the description of grounding above:

They discussed the design problems in various places in the building to be constructed by zooming in and out of the combined model and pointing at locations on it. A prominent feature of these meetings was the frequent use of indexical signs during the discussions. The participants indicated those places in the plans that were problematic using the cursor, with indexical utterances, with their hands andby zooming in and out and moving the model.

\section{AVOIDING VISUAL OVERBURDENING}

The method of $5 \mathrm{~S}$ has been presented as part of visual controls. This Japanese method achieves organisation of the workplace through cleanliness, rejection of unneeded items, and order. How can this be explained?

Based on their review of literature, Jackson and Calvillo (2013) conclude that high perceptual load increases response time, narrows attention, and increases error rates. Johnson-Laird (2010), a leading scholar in psychology, claims that irrelevant visual detail impedes reasoning: "Images impede reasoning, almost certainly because they call for the processing of irrelevant visual detail." Spagnol, de Campos and Li (2015) report a study on brain activation during different levels of $5 \mathrm{~S}$ application. The findings show significant increased brain activation in the last task (at the highest level of application) when compared to the first, suggesting that $5 \mathrm{~S}$ facilitates brain pathways for information processing. Maeda's (2006) call for simplicity resonates with the views and results just presented.

Thus, there is evidence suggesting that absence of irrelevant visual detail, resulting from the application of 5S, facilitates the direct capture of relevant visual information and reasoning involving visual data.

\section{CREATING ADHERENCE}

In VM, the abstract concept of discipline is transformed into directly observable concrete practices (Mann, 2005). In view of this, VM can be seen as visual rhetoric, targeting adherence by the audience (Koskela 2015).

The theory of production shows that the reduction of variability (uncertainty) is, at the end, the single most important means against waste. Thus, adherence to standards for work and its outputs is paramount. The objective of rhetoric is precisely to create adherence. This connection offers the opportunity of making the rich legacy of rhetoric to bear on understanding and designing VM. What is needed is research identifying, trying out and evaluating rhetorical principles and their efficiency in VM.

6 Visual management is usually based on tangible artefacts. BIM represents the new trend towards information technology based visual management (Tezel \& Aziz 2017). 


\section{WHY IS VISUAL MANAGEMENT PREFERRED IN SOME MANAGERIAL APPROACHES AND NOT IN OTHERS?}

VM is much associated to lean production. There are instances of VM in other fields, such as healthcare and air traffic control, but they are seen as exceptions and there has been a long-standing tendency to replace tangible visual devices by computer systems and displays and screens. How can these split views be explained?

Lean production is an approach that puts production to be at the centre of the organisation; organising is structured to facilitate the achievement of goals related to production. Reduction of waste requires reduction of cycle times and variability. Mental operations, such as communication and decision-making are strictly seen waste in production; they are not adding value to the customer. Through VM, communication and decision-making can be sped up. On the other hand, the higher reliability of VM translates into lower variability. Thus, VM has emerged as an intrinsic part of lean production as it is compatible with its first principles.

Regarding then the mainstream approach to management and organization, the crucial factor is that since the 1960s, production as a phenomenon has been pushed outside these fields (Koskela 2017), and thus the operational benefits of VM remain invisible. This might explain the lack of interest in these fields.

\section{CONCLUSIONS}

If anything, the reported explorations towards theoretical foundations show that visual management is at a fascinating crossroads of different phenomena, and of disciplines, old and new, addressing them. Several angles and levels will probably be needed for creating a practically complete theoretical account of visual management. However, already the existing crumbles of insight are useful and pinpoint direction, both for empirical research, development of design guidelines, and practical development.

\section{REFERENCES}

Bell, E., \& Davison, J. (2013). Visual management studies: Empirical and theoretical approaches. International Journal of Management Reviews, 15(2), 167-184.

Beynon-Davies, P. \& Lederman, R. (2016). Making sense of visual management through affordance theory. Production Planning \& Control, DOI: 10.1080/09537287.2016.1243267

Clark, H. H., \& Brennan, S. E. (1991). Grounding in communication. Perspectives on socially shared cognition, 13(1991), 127-149.

Cross, N., and Cross, A.C. (1995). Observations of teamwork and social processes in design. Design studies,16(2), 143-170.

Eppler, M.J. \& Bresciani, S. (2013). Visualization in Management: From Communication to Collaboration. J.of Visual Languages and Computing, 24(2), 146-149.

Galsworth, G.D. (1997). Visual systems: harnessing the power of the visual workplace. American Management Association.

Gergle, D., Kraut, R.E., \& Fussell, S.R. (2013). Using visual information for grounding and awareness in collaborative tasks. Human-Computer Interaction, 28(1), 1-39.

Gibson, J. (1979). The theory of affordances. The people, place, and space reader, pp. 56-60. 
Hettinger, A.Z., Roth, E.M., \& Bisantz, A.M. (2017). Cognitive engineering and health informatics: applications and intersections. J. of Biomedical Informatics, 67, 21-33.

Jackson, R.E., \& Calvillo, D.P. (2013). Evolutionary relevance facilitates visual information processing. Evolutionary Psychology, 11(5), 147470491301100506.

Johnson-Laird, P.N. (2010). Mental models and human reasoning. Proceedings of the National Academy of Sciences, 107(43), 18243-18250.

Kahneman, D. (2011). Thinking, Fast and Slow. Penguin Books.

Klein, G., Feltovich, P.J., Bradshaw, J.M., \& Woods, D.D. (2005). Common ground and coordination in joint activity. Organizational Simulation, 53, 139-184.

Koskela, L. (2015). Where Rhetoric and Lean Meet. In: Seppänen, O., González, V.A. \& Arroyo, P., 23rd Annual Conference of the International Group for Lean Construction. Perth, Australia, 29-31 Jul 2015. Pp 527-535.

Koskela, L. (2017). Why is management research irrelevant?Construction management and economics, 35(1-2), 4-23.

Koskela, L., Pikas, E., Gomes, D., Biotto, C., Talebi, S., Rahim, N. and Tzortzopoulos, P. (2016). Towards Shared Understanding on Common Ground, Boundary Objects and Other Related Concepts. In: The 24th Annual Conference of the International Group for Lean Construction, 18 - 24 July 2016, Boston, USA.

Kraut, R.E., Gergle, D., \& Fussell, S.R. (2002). The use of visual information in shared visual spaces: Informing the development of virtual co-presence. Proceedings of the 2002 ACM conference on Computer supported cooperative work, pp. 31-40.

Landi, N. (2010). An examination of the relationship between reading comprehension, higherlevel and lower-level reading sub-skills in adults. Read Writ, 23(6), 701-717.

Lewis, T. (2014).New Record for Human Brain: Fastest Time to See an Image. LIVESCIENCE. https://www.livescience.com/42666-human-brain-sees-images-record-speed.html

MacKay, W. E. (1999). Is paper safer? The role of paper flight strips in air traffic control.ACM Transactions on Computer-Human Interaction, 6(4), 311-340.

Maeda, J. (2006). The laws of simplicity. MIT Press.

Maher, M.L., Cicognani, A. \& Simoff, S. (1996). An experimental study of computer mediated collaborative design. Proceedings of WET ICE' 96.

Mann, D. (2005). Creating a Lean Culture: Tools to Sustain Lean Conversions. Productivity Press.

Medeiros, B.C. (2017). Life Cycle Canvas (LCC): análise de um modelo de gestão visual para o planejamento de projetos. Tese (Doutorado em Administração). Universidade Federal do Rio Grande do Norte.

Miettinen, R., \& Paavola, S. (2016). Reconceptualizing object construction: the dynamics of Building Information Modelling in construction design. Information Systems Journal. DOI: 10.1111/isj. 12125

Osterwalder, A., \& Pigneur, Y. (2010). Business model generation: a handbook for visionaries, game changers, and challengers. John Wiley \& Sons.Spagnol, G.M, de Campos, B.M., \& Li, L.M. (2015). Understanding 5S: How Does Visual Management Activate Our Brain? Proc.of IIE Engineering Lean and Six Sigma Conf.

Springer, S.P., Deutsch, G. 1993. Left Brain, Right Brain. W.H. Freeman and Company.

Tezel, A.\& Aziz, Z. (2017). From conventional to IT based visual management: a conceptual discussion for lean construction. J.of Inf.Technology in Construction, 22, 220-246

Tezel, B. A., Koskela, L., \& Tzortzopoulos, P. (2009). The functions of visual management.Proceedings of the International Research Symposium,Salford, UK. Pp. 201 210. 
Tezel, A., Koskela, L., \& Tzortzopoulos, P. (2016). Visual management in production management: a literature synthesis.J. of Manuf. Technology Management, 27(6), 766-799.

Tversky, B. (2011). Visualizing thought. Topics in Cognitive Science, 3(499-535).

Tversky, B. (2015). The cognitive design of tools of thought. Review of Philosophy and Psychology, 6(1), 99-116.

Valente, C., Brandalise, F., Pivatto, M. \& Formoso, C. (2017). Guidelines for Devising and Assessing Visual Management Systems in Construction Sites.25th Annual Conf.of the Int.Group for Lean Construction. Heraklion, Greece, 9-12 July 2017. Pp. 695-702.

Vicente, K.J., \& Rasmussen, J. (1992). Ecological interface design: Theoretical foundations. IEEE Transactions on systems, man, and cybernetics, 22(4), 589-606.

Von Uexküll, J. (1926). Theoretical Biology, transl. by D.L. MacKinnon. London, Kegan.

Wickens, C.D., Lee, J., Liu, Y.D. \&Gordon-Becker, S. (2014). An introduction to human factors engineering. Pearson Education.

Wilson, K.M., Helton, W.S., \& Wiggins, M.W. (2013). Cognitive engineering. Wiley Interdisciplinary Reviews: Cognitive Science, 4(1), 17-31.

Xiao, Y. (2005). Artifacts and collaborative work in healthcare: methodological, theoretical, and technological implications of the tangible. J. of Biomedical Informatics, 38(1), 26-33. 